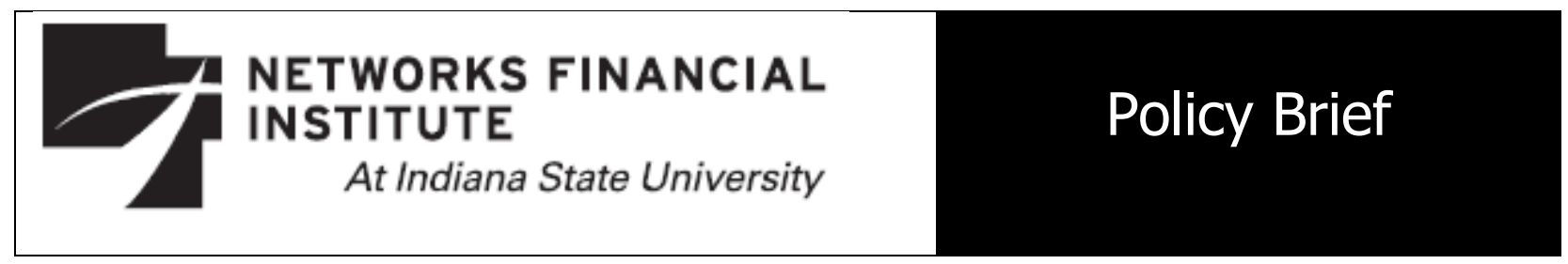

2011-PB-09

October 2011

\title{
The Continuing Debate on Health Insurance Reform
}

Scott E. Harrington

Abstract: This Policy Brief provides an overview of the 2010 Affordable Care Act and perspective on some of its key provisions affecting health insurance. Following a synopsis of the main problems that confront U.S. health care and insurance, it considers the extent to which the Affordable Care Act (ACA) will affect those problems, including the ACA's minimum medical loss ratio and rate review requirements for health insurers. It discusses the economics of the individual mandate, implications of possible court rulings on the mandate's constitutionality, and implementation of the ACA to date. It concludes with brief description of market-oriented alternatives to the ACA that will likely be considered if the Republicans win the 2012 presidential election, retain the House, and capture a sufficient majority in the Senate.

About the Author: Scott E. Harrington, Ph.D. (http://www.scottharringtonphd.com/) is the Alan B. Miller Professor in the Health Care Management at the Wharton School, University of Pennsylvania. He is an adjunct scholar for health policy at the American Enterprise Institute. A former President of both the American Risk and Insurance Association and the Risk Theory Society, he is a Co-Editor of the Journal of Risk and Insurance and has published widely on the economics and regulation of insurance. A frequent speaker on health insurance reform, insurance markets, regulation, and public policy, he has conducted research, consulted, or served as an expert for many organizations. He has testified before the U.S. House and Senate on insurance regulation and before numerous U.S. state legislative and administrative committees. His recent policy research has focused on healthcare reform and on the causes and implications of the financial crisis for insurance regulation.

Keywords: Affordable Care Act; individual mandate; market-oriented alternatives.

The views expressed are those of the individual author and do not necessarily reflect official positions of Networks Financia I Institute. Any errors or omissions are the responsibility of the author. Please address questions regarding content to Scott Harrington at harring@wharton.upenn.edu, or visit his website at www.scottharringtonphd.com. NFI working papers and other publications are available on NFI's website (www.networksfinancialinstitute.org). Click "Thought Leadership" and then "Publications/Papers." 


\section{Introduction}

The U.S. House of Representatives passed the Patient Protection and Affordable Care Act (“Affordable Care Act” or “ACA") on March 21, 2010 by a 219-212 vote, with no Republican support. The Senate had passed the bill on December 24, 2009, by a 60-39 vote with no Republican support. After approving the ACA, the House passed a package of amendments in the Health Care and Education Reconciliation Act of 2010, which, with minor changes, was approved by the Senate and again by the House on March 25. President Obama signed the original ACA on March 23 and the final reconciliation bill on March 30, 2010, completing the most significant social legislation in the United States since the enactment of Medicare and Medicaid in 1965. Absent repeal or a Supreme Court holding that all or part of the law is unconstitutional, the ACA will expand health insurance coverage by (1) requiring individuals beginning in 2014 to obtain qualified health insurance or pay a fine; (2) subsidizing the cost of coverage for low-to-moderate income persons and for small, low-wage employers; (3) requiring employers with 50 or more employees to offer health coverage or pay fines; and (4) expanding eligibility for publicly-funded Medicaid programs.

The ACA requires the establishment in 2014 of state-based health insurance exchanges for the individual and small group markets, with premium subsidies available only for coverage purchased through an exchange. Apart from any grandfathered plans, health insurers will be restricted to offering within or outside of the exchanges no more than four coverage tiers, along with a catastrophic plan for young adults. They must accept all applicants regardless of health status and without excluding preexisting conditions. Individual and small group premiums will be permitted to vary only by coverage tier, number of dependents, geographic region, age (within a 3-1 ratio), and tobacco use (1.5-1 ratio).

Beginning in 2011, health insurers' spending on medical care and activities that improve health care quality must equal or exceed $85 \%$ of premiums (net of certain taxes and fees) for large group coverage and $80 \%$ of premiums for individual and small group coverage. Health insurers also must justify "unreasonable" rate increases, and insurers with "unreasonable" increases may be excluded from the exchanges. Other ACA-mandated changes that have taken effect include creation of temporary pools 
for previously uninsured people with pre-existing conditions, prohibition of pre-existing condition exclusions for children, mandating coverage of enrollees' adult children up to age 26, restriction/elimination of annual/lifetime benefit limits, and prohibition of health insurance policy rescissions absent fraud.

The future of the ACA is uncertain judicially and legislatively, and the debate over its efficacy remains intense 18 months after enactment, especially concerning its mandate for individuals to have health insurance. This policy brief provides an overview of the law and perspective on some of its key provisions affecting health insurance. ${ }^{1}$ Following a synopsis of the main problems that confront U.S. health care and insurance, it considers the extent to which the ACA will affect those problems, including the ACA's minimum medical loss ratio and rate review requirements for health insurers. It discusses the economics of the individual mandate, implications of possible court rulings on the mandate's constitutionality, and implementation of the law to date. It concludes with brief description of marketoriented alternatives to the ACA that will likely be considered if the Republicans win the 2012 presidential election, retain the House, and capture a sufficient majority in the Senate.

Section II provides an overview of high and growing health care costs, federal health care spending, large numbers of people without health coverage, health insurance market performance, and broad methods for dealing with unsustainable health care cost growth. Section III summarizes the ACA's key provisions; Section IV considers its potential effects and implementation to date. Section V briefly outlines market-oriented alternatives to the ACA.

\section{The Context of Reform}

\section{High and Rapidly Growing Medical Costs}

Figure 1 shows U.S. health expenditures as a percentage of Gross Domestic Product (GDP) overall and by major source of spending during 1965-2010 (projections for 2010). In conjunction with substantial real growth in per capita medical spending, the percentage of GDP devoted to health care grew

\footnotetext{
${ }^{1}$ Parts of this paper draw from or expand upon my earlier work, especially Harrington (2010b and 2010c).
} 
from under six percent to nearly 18 percent during that time, an amount far above other countries. For 2010, projected Medicare/Medicaid spending represented 6.4 percent of GDP. Private health insurance spending (including employer-sponsored self-funded plans) represented 5.7 percent of GDP. Other $3^{\text {rd }}$ party spending, including federal and state spending on the Childrens' Health Insurance Plan (CHIP), represented 3.7 percent of GDP. ${ }^{2}$ In contrast to growing shares of public and private insurance and other $3^{\text {rd }}$ party reimbursement, out-of-pocket spending represented a lower percentage of GDP in 2010 (2.1 percent) than in 1965 (2.5 percent).

High and growing per capita health expenditures and more prevalent $3^{\text {rd }}$ party payment have been accompanied by high and growing average health insurance premiums. The Kaiser/HRET survey of employer-sponsored health benefits, for example, reports an average premium (employer and employee combined) for family coverage in 2011 of $\$ 15,073$, with an average worker contribution of $\$ 4,129$ (Kaiser/HRET, 2011). Given greater average cost-sharing and less generous benefits chosen, average individual health insurance market premiums are much lower. According to an AHIP survey of 2.5 million policies, the average premium for family coverage in 2009 was $\$ 6,328$ (AHIP, 2009), compared with $\$ 13,375$ in the 2009 Kaiser/HRET survey (Kaiser/HRET, 2009). The high costs of health care and insurance influence many people to forego coverage.

Explanations of why the U.S. spends much more on health care than other countries generally point to significantly higher compensation of health care providers and historically greater rates of technology adoption and diffusion, along with the lesser role played by government and correspondingly greater private sector role in financing medical care. ${ }^{3}$ The extent to which higher U.S. spending is associated with higher quality of health care and whether higher quality is worth the cost plays a significant role in the policy debate.

\section{Medicare and Medicaid Spending}

\footnotetext{
${ }^{2}$ The NHE data include federal and state spending on CHIP, a Medicaid-type public program, as part of "other" $3^{\text {rd }}$ party spending, which also includes, e.g., military health care and workers' compensation spending.

${ }^{3}$ McKinsey (2008) provides detailed background on U.S. costs and international comparisons.
} 
Large projected increases in Medicare spending and Medicaid cost growth represent critical problems confronting U.S. health care and federal/state government finance. Medicare funding poses major challenges from real cost increases per enrollee and aging of the population. The Medicare Boards of Trustees (2011) estimated the present value of the projected Medicare unfunded liability under current law over the next 75 years at \$24 trillion as of year-end 2010 (using their intermediate economic assumptions). The Trustees projected that the hospital insurance trust fund will exhaust in 2024. The projections assume a 30 percent reduction in physician reimbursement beginning in 2012 under the Sustainable Growth Rate system, which Congress has repeatedly overridden with stopgap measures. They also assume significant cuts in non-physician provider reimbursement under the ACA (see below). Thus, it is likely that the hospital insurance fund will be exhausted well before 2024 .

Figure 2 shows projected Medicare spending as a proportion of GDP during 2010-2050 from the 2009 Trustees' report (prior to the ACA) and the Trustees' 2011 report based on current law. It also shows alternative projections as of 2011 from the Center for Medicare and Medicaid Services (CMS, 2011), which, according to CMS, assumes more realistic spending for physician and hospital reimbursement.

\section{The Uninsured}

Figure 3 shows estimated proportions of the U.S. population under age 65 without health insurance and with employer-sponsored, directly purchased (individual), and Medicaid coverage during 2001-2010 based on the Current Population Survey (CPS). ${ }^{4}$ An estimated 49 million U.S. residents under age 65 did not have health insurance in 2010 , representing 18.4 percent of the under age 65 population. ${ }^{5}$ As is shown in Figure 4, the likelihood of adults being uninsured generally declines significantly with age. Approximately 28 percent of people age 18-34 were estimated as uninsured in 2010 compared with approximately 15 percent of people aged 55-64. With the exception of the age 18-24 category, where the

\footnotetext{
${ }^{4}$ Other insured people under age 65 had Medicare or military coverage. Some people had more than one source of coverage.

${ }^{5}$ The estimated 50 million uninsured of all ages represented 16.3 percent of the total population. Kaiser Family Foundation (2009) provides detailed estimates of the uninsured and their characteristics.
} 
estimated uninsured rate dropped in 2010, the estimated uninsured rates for each age group have increased since $2007 .^{6}$

Compared with the insured non-elderly, the uninsured on average have significantly lower income and educational attainment, are less likely to be employed full time, are more likely to be black and/or of Hispanic origin, and are less likely to report being in excellent or very good health. It has been estimated in recent years that roughly a quarter of the uninsured were eligible for Medicaid, but had not enrolled, that roughly 10 million lived in households where a member declined employer-sponsored coverage, that 4-5 million or more had incomes above 400 percent of the federal poverty level, and at least several million were unauthorized residents (Kaiser Family Foundation, 2009; NIHCM, 2008).

Estimates suggest that the uninsured paid about a third of the cost of their medical care and produced an estimated $\$ 56$ billion in uncompensated care for providers in 2008, with government funding covering about 75 percent of the cost of uncompensated care (Hadley, et al., 2008). While statistical and econometric analyses have not been definitive (Levy and Meltzer, 2009), the general consensus is that a lack of insurance negatively affects access to health care and health. The uninsured are entitled to hospital emergency/acute care to stabilize their conditions without regard to ability to pay, and many uninsured with low incomes obtain care from community health centers. But being uninsured on average is associated with a lower likelihood of having a usual source of medical care, less use of preventive medical care, greater likelihood of foregoing medical care due to cost, and, while the magnitude of the increase is debated, a greater likelihood of bankruptcy due to unpaid medical bills. In contrast to continuing and even increasing concern with the number of people without insurance, Figure 5 shows that the proportion of total U.S. health care expenditures paid by patients out of pocket versus being reimbursed by insurance or other $3^{\text {rd }}$ party payment has decreased more or less steadily since 1965 . The proportion paid out-of-pocket declined from 43 percent in 1965, when Medicare and Medicaid were

\footnotetext{
${ }^{6}$ The decline in the uninsured rate for the age 18-24 group in 2010 might reflect in part early effects of the ACA's requirement that children be allowed to stay on parents' coverage through age 25 .
} 
enacted, to 22 percent in 1985 and 12 percent by 2010. The proportion declined in recent years even though the proportion of the U.S. population without insurance was relatively stable or increasing.

\section{Insurance Market Performance}

Insurers' administrative expenses and profits. The ACA's minimum medical loss ratio and health insurance rate review provisions (discussed below) reflect views that health insurance competition and pre-ACA state regulation did not adequately discipline insurers' expenses and profits and that federal regulation and oversight of health insurers was needed. Aggregate data, however, suggest that health insurers' expenses and profits are not major drivers of high and rapidly growing health insurance premiums. According to National Health Expenditure (NHE) data, the projected "net cost" of private health insurance (premiums less benefits, including for self-funded plans) for 2010 was $\$ 96$ billion, representing 11.7 percent of projected expenditures for private health insurance and 3.7 percent of projected total health care expenditures. ${ }^{7}$ The estimated medical loss ratio for all private health insurance (ratio of medical benefits to total premiums, including premium equivalents for self-funded plans) has averaged 87.7 percent since 1965 , with little or no trend (see Figure 6). ${ }^{8}$

Health insurers' profit margins typically average about 3-5 percent of revenues (less for nonprofit insurers). Medical loss ratios for insured plans average roughly 85 percent (higher for nonprofits than for-profits); administrative expense ratios average about 11 to 12 percent. ${ }^{9}$ Expense and profit data reported to state insurance regulators during 2006-2009 indicate that aggregate medical loss ratios ranged from 85 to 88 percent for all insured coverage (including Medicare supplement and Medicare Advantage plans) and from 83 to 87 percent for comprehensive major medical coverage (Donahue, 2010).

\footnotetext{
${ }^{7}$ The data (http://www.cms.gov/) are from NHE tabulations by type of expenditure and source of funds, calendar years 1965-2020, with projections for 2010-2020. The projections are based on the 2009 version of the NHE accounts released in January 2011.

${ }^{8}$ The NHE data report estimated premium expenditures and the estimated difference between premiums and benefits (denoted the "net cost" of private health insurance in the expenditure accounts). The ratios in Figure 6 equal one minus the ratio of net cost to premiums.

${ }^{9}$ Harrington (2010a) summarizes other evidence from a variety of sources.
} 
Market concentration. Commercial health insurance market concentration is often high at the state and metropolitan levels, especially for individual insurance (e.g., Robinson, 2004, American Medical Association, 2007, Government Accountability Office, 2009, Kaiser Family Foundation, 2011). High concentration does not necessarily imply adverse effects on consumers (e.g., Conover and Miller, 2010). Market concentration is highly correlated with Blue Cross Blue Shield plan market shares. Many large Blues are nonprofit and operate with high medical loss ratios and very low profit ratios, making it difficult for other insurers to gain share. Consolidation in many health insurance markets has coincided with consolidation among hospitals and hospital-provider networks, in some cases increasing insurers' ability to negotiate favorable rates with providers, and in other cases the opposite, depending on relative bargaining leverage. ${ }^{10}$ Third-party administrators and employer self-funding and administration in general represent significant sources of competition for insurance companies in the employer-sponsored market, except for small-group coverage.

Antitrust exemption for business of insurance. The limited antitrust exemption for the "business of insurance" has little effect on health insurers; there is no evidence that it has raised prices, profits, or market concentration. Insurers' relationships with medical care providers, such as the inclusion of "most favored customer" clauses in contracts with hospitals, are not protected. In contrast to property/casualty insurance, health insurance has no history of joint ratemaking activity that is protected by the exemption. Health insurer mergers have been subject to federal antitrust jurisdiction since at least the early 1970s, and mergers and acquisitions of health insurers are subject to approval by state regulators.

Underwriting and risk classification practices. Health insurers' underwriting and risk classification practices received widespread criticism during the pre-ACA debate. When permitted by law, insurers generally consider the applicant's health when deciding whether to provide coverage and at

\footnotetext{
${ }^{10}$ Research has provided mixed evidence of the effects of increased concentration on healthcare markets (see, for example, Dafny, 2008; Dafny, Duggan, and Ramanarayanan, 2009; Moriya, Vogt, and Gaynor, 2010; also see Conover and Miller, 2010, and Gaynor and Town, 2011).
} 
what terms. ${ }^{11}$ Applicants with pre-existing health conditions will face higher than average premiums, more limited coverage, and/or not be offered any coverage. While state and federal law pre-ACA generally required insurers to offer coverage to persons previously insured for minimum periods of time, they did not require insurers to offer coverage at rates that do not reflect health status. People who develop costly pre-existing conditions at a young age may face high premiums and/or limited coverage in the individual market. People with pre-existing conditions who lose employer-sponsored coverage and exhaust their ability to continue coverage under federal and state law may face high individual market premiums and/or exclusion of coverage for one or more pre-existing conditions. ${ }^{12}$ While the number of people that are uninsured because of pre-existing conditions, termination of insurance after job loss, and/or exhaustion of continuation of coverage benefits is not known, those sources of uninsurance and difficulty in affording health insurance were regarded as problematic.

Policy Rescissions. Traditional practice, governed by common law, statute, and regulation, is for insurers to rely on accurate disclosure of health-related information by applicants without conducting a detailed investigation of medical history. Companies often practice ex post auditing - conducting more detailed and costly reviews of a subset of applications following policy issue - sometimes when expensive treatment is sought soon after issue. Before the ACA, state laws generally permitted rescission of coverage (declaring the policy void) on the basis of material misrepresentation, i.e., providing incorrect information that affected the insurer's decision to offer coverage or the premium charged. Thus, while coverage could not be cancelled because of sickness, it generally could be rescinded if information was provided by the applicant is false and affected the insurer's decision.

\footnotetext{
${ }^{11}$ Once issued, most policies are guaranteed to be renewable at rates that change with the experience of a given risk pool rather than the health status of an individual policyholder. If policyholders that remain healthy tend to seek out new coverage and leave a given risk pool, the rates for those who remain will increase accordingly. A sizable literature has considered the extent to which guaranteed renewable coverage will be stable. Most states and federal law include regulations that promote guaranteed renewable coverage.

${ }^{12}$ According to AHIP (2009) survey data, the overall denial rate for the individual insurance market was 12.7 percent in 2009, ranging from about 10 percent for applicants under age 35 to roughly 30 percent for applicants aged 60-64. The extent to which applicants denied coverage were able to obtain coverage from another insurer or source is not known. The AHIP survey reported that 34 percent of offers were at higher than standard premium rates (29 percent of the offers were at standard rates and 36 percent were below standard rates) and that six percent of offers included a waiver of coverage for one or more health conditions.
} 
Health insurance rescissions generated substantial controversy, litigation, and in some states new regulation prior to the ACA, and the issue played an important role in the debate preceding its enactment, including Congressional hearings and emphasis on the issue by President Obama. Along with the controversy over pre-existing condition exclusions, the controversy over rescission, and to a lesser extent general claims settlement, contributed to an impression that health insurers' practices were insufficiently and ineffectively regulated.

\section{Dealing with Unsustainable Spending Growth}

As elaborated below, the ACA is unlikely to "bend the cost curve" significantly. Some provisions will help reduce spending growth; others will increase spending. Insurance market problems notwithstanding, historical and projected growth rates in public and private spending on healthcare in the United States remain unsustainable. A significant majority of health economists agree that a primary driver of unsustainable cost growth is incentive misalignment in health care payment and delivery. U.S. payment/delivery has four characteristics: (1) relatively generous insurance coverage for most people with insurance, (2) only modest restrictions on choice of providers and access to specialists, (3) a prevalence of fee-for-service payment to providers, and (4) an absence of overt government limits on total spending. This system encourages cost growth generally and excessive utilization of low-valued health care specifically. Many economists attribute much of the underlying problem to tax subsidies to employer-sponsored coverage and to Medicare subsidies and coverage design.

Given this view, there are two broad avenues for achieving sustainable cost growth: (1) adopting progressively tighter government controls on provider payment and delivery of care, or (2) adopting market-oriented policies that provide patients and providers with greater incentives for cost control. This choice confronts Medicare as well as private coverage.

The polar views of the causes and solutions to problems in U.S. health care were brought into sharp relief by the debate over the ACA. Liberals/progressives view the United States' significant reliance on private health insurance as wasteful and unjust. The ultimate goal of many is a system of universal health 
insurance with a single, government payer, such as "Medicare for all." Mandating individuals to have health insurance and allowing choice of government coverage through a "public plan option" are viewed as important steps in achieving that goal. Conservatives view high costs and spending growth as largely due to misalignments in incentives that produce too much insurance of the wrong type for many people. The results include too much utilization of costly, low-value medical care for people with coverage and coverage that is too expensive for many to afford. The proposed solution is to improve incentives through changes in the tax system and greater reliance on competition and consumer choice to control costs, without significantly greater government restrictions on reimbursement and providers. These conflicting visions contributed to the partisan divide that produced the ACA. 


\section{Key Provisions of the ACA}

\section{Coverage Expansion}

The ACA is highly complex, with numerous provisions affecting patients, providers, employers, health insurers, and taxpayers. ${ }^{13}$ Its key provisions for expanding coverage are patterned after reforms adopted in Massachusetts in 2006.

Individual mandate. Beginning in 2014, most legal residents who meet income tax filing thresholds will be required to have health insurance that meets minimum requirements, unless the cost of minimum qualified coverage exceeds 8 percent of their income. The penalty for non-compliance with the "individual mandate" will be the greater of $\$ 95$ (up to three times that amount for families) or 1 percent of taxable income in 2014 , increasing to the greater $\$ 695$ or 2.5 percent of taxable income in 2016 , and indexed to inflation in later years.

Premium tax credits and cost-sharing subsidies. Beginning in 2014, premium tax credits will be provided to individuals/families with income between 133-400 percent of the Federal Poverty Level (FPL). The credits will limit premium contributions to specified percentages of income (e.g., 3-4 percent for incomes between 133 and 150 percent of FPL, increasing to 9.5 percent for incomes between 350 and 400 percent of FPL). The law also reduces cost-sharing for persons with incomes up to 400 percent of FPL, with greater reductions for lower income individuals/families.

Employer mandate and penalties. Businesses with 50 or more employees that do not offer health coverage and have one or more full-time employees receiving a premium credit will pay a penalty of $\$ 2,000$ per full-time employee excluding the first 30 employees. Businesses with 50 or more employees that offer coverage to employees will pay a penalty of $\$ 3,000$ per employee if one or more of their employees receive a premium tax credit for coverage outside of employment, again excluding the first 30 employees.

\footnotetext{
${ }^{13}$ Kaiser Family Foundation (2011c) provides a detailed summary of the law.
} 
Small employer tax credits. Employers with 25 or fewer employees and with annual wages averaging less than $\$ 50,000$ are eligible for tax credits for offering coverage beginning with the 2010 tax year. The credit varies over time and phases out as a function of the number of employees and average wages.

Medicaid expansion. Eligibility for the taxpayer funded Medicaid program will be expanded in 2014 to all non-Medicare eligible people with incomes up to 133 percent of the FPL and will include nondisabled, nonelderly adults without dependent children. The coverage will include the essential benefits package as specified in the law (see below). The federal government will finance 100 percent of the cost of Medicaid expansion through 2016, gradually declining to 90 percent in 2020 and later.

Pre-existing condition insurance plans. The ACA created a temporary program to provide subsidized coverage at the state level to individuals with pre-existing medical conditions who have been uninsured for at least six months. The plans are intended to serve as a stopgap until the law's main provisions take effect in 2014.

\section{Insurance Market Regulation}

State health insurance exchanges. The ACA promulgates the establishment of state-based health insurance exchanges for the individual market and for the small group market for firms with up to 100 employees in 2014. States are permitted to allow larger employers to purchase exchange coverage beginning in 2017. States have the choice of establishing and operating their own exchanges or having the federal government establish and run them. ${ }^{14}$ About a quarter of the states have enacted legislation to create exchanges (Kaiser Family Foundation, 2011a). It is not clear how many others will follow. The HHS is working on rules governing the exchanges.

Benefit tiers. A minimum essential benefits package will be established for individual and small group coverage in 2014 and later years. The minimum benefits will cover at least 60 percent of the actuarial value of eligible benefits with maximum cost-sharing equal to health savings account

\footnotetext{
${ }^{14}$ States are permitted to join compacts to establish multi-state exchanges.
} 
maximums. Insurers participating in the exchanges and those offering coverage outside of an exchange will be restricted to offering four coverage tiers, along with a catastrophic plan for young adults in the individual market. Bronze, Silver, Gold, and Platinum plans will cover 60 percent, 70 percent, 80 percent, and 90 percent, respectively, of plan benefit costs. ${ }^{15}$ States are permitted to establish Basic Health Plans for people with incomes between 133 and 200 percent of the federal poverty level who would be eligible for exchange subsidies and receive 95 percent of the subsidy that would have been paid to the exchange.

Mandatory offers at community rates. Going beyond existing restrictions in all but a few states, beginning in 2014 health insurers will have to accept all applicants regardless of health status, without basing premiums on health status or excluding coverage for pre-existing conditions. Premium rates will be allowed to vary only by coverage tier, number of dependents, geographic region, age (within 3-1 ratio), and tobacco use (1.5-1 ratio).

Immediate coverage requirements. The ACA includes a number of other "immediate" changes to private health insurance (generally effective 6 months after enactment). These include (1) prohibition of pre-existing condition exclusions for children, (2) mandatory coverage of preventive services without patient cost sharing, (3) extension of coverage to adult children up to age 26 for all individual and group plans, and (4) elimination of lifetime benefit limits 6 months after enactment and restrictions on annual benefit limits prior to their elimination in 2014.

Grandfathered plans. Health plans in existence as of the ACA's enactment in 2010 do not need to meet the law's benefit requirements with a number of important exceptions. Otherwise grandfathered plans must not exclude coverage of pre-existing conditions for children 6 months after enactment and for adults as of 2014. They also must extend dependent coverage to children up to age 26 and eliminate/restrict lifetime/annual benefit limits. Grandfathered status is lost if a health plan makes certain changes, such as increasing the deductible or employee premium contribution above specified thresholds.

\footnotetext{
${ }^{15}$ The law does not specify specific plan designs for meeting the actuarial value targets. Massachusetts' 2006 reform law was later modified to restrict variation among plan design within a given tier.
} 
Many employer-sponsored plans have already lost or are expected to lose grandfathered status during the next few years.

Minimum medical loss ratios and rate review. As discussed further below, beginning in 2011 health insurers must spend an amount on medical costs and "activities to improve quality" of care equal to a minimum of 85 percent of premiums net of certain taxes for large group coverage and 80 percent of premiums for individual and small group coverage, with insurers required to pay rebates to policyholders if required to achieve those minimums. Health insurers are also required to justify "unreasonable" rate increases to state regulators and to the HHS.

\section{Projected Costs and Financing}

Figure 7 shows Congressional Budget Office (CBO, 2011b) projections as of March 2011of the ACA's impact on federal spending and revenues for the 10-year period 2012-2021 (from the CBO's score of House Republican legislation to repeal the law). The CBO projects a gross cost (before offsets for individual and employer penalties) of coverage expansion during that period of approximately $\$ 1.4$ trillion. That cost is roughly divided between exchange premium subsidies and Medicaid expansion. Coverage expansion will be financed by Medicare and Medicaid spending cuts (primarily from Medicare), by a variety of new taxes, and from penalties on non-complying employers and individuals.

New taxes include a Medicare (hospital insurance) tax equal to 3.8 percent of unearned income for taxpayers with adjusted gross incomes above $\$ 200,000$ for individuals and $\$ 250,000$ for joint filers (thresholds not indexed). That tax and an additional 0.9 percent Medicare hospital insurance tax on earned income for those filers are projected to generate $\$ 259$ billion during 2012-2021. Other new taxes include a projected $\$ 148$ billion of levies on health insurance, pharmaceutical, and medical device companies, and $\$ 111$ billion from an excise tax on high cost health plans (see below). As elaborated below, the CBO estimates that the law would reduce federal deficits by $\$ 231$ billion during 2012-2021 (up from an estimated $\$ 143$ billion of deficit reduction for 2010-2019 at the time of enactment, $\$ 145$ billion and $\$ 73$ billion, respectively, without the CLASS program). 


\section{Effects of the ACA}

\section{Projected Increase in Number of Insured}

The CBO projected in March 2011 (CBO, 2011a) that the ACA would result in 34 million more people with health insurance in 2021 than if the law had not been passed (see Figure 8). The projected proportion of the population without health insurance would be 8 percent ( 5 percent of authorized residents) compared with a projection of 20 percent (17 percent of authorized residents) without the law. Half of the projected 34 million newly insured would be covered by Medicaid and half by private health insurance.

The CBO projects that the law will have relatively little effect on the number of people with employer sponsored coverage. Despite that projection, the law's potential effects on employers' decisions to offer coverage are subject to ongoing debate (as well as the law's potential effects on employment). The ultimate effects on employers' decisions to offer health coverage depend on complex incentives and influences, including the magnitude of employer fines for not offering coverage (or having employees reject coverage and obtain subsidized coverage through an exchange), the amount of additional wages employers must pay if they do not offer health coverage, the scope of minimum essential benefit rules that affect the cost of coverage, and potential efficiencies from health insurance exchanges. The continued tax advantages of employer sponsorship, scale economies of employer provision, and reduced adverse selection for group coverage favor a robust employer-sponsored market going forward. Like the CBO projections, many researchers and analysts believe that the ACA's impact will be relatively modest, with the main depressing effects falling primarily on smaller, lower wage firms. But considerable uncertainty exists, and some analyses and surveys raise the possibility of significant reductions in employer sponsorship.

\section{Impact on the Federal Deficit}

The latest and earlier CBO projections of the ACA's impact on federal budget deficits have been subject to considerable debate. Of the $\$ 231$ billion for 2011-2021, \$86 billion ( $\$ 70$ billion for 2010-2019 
at the time of enactment) is due to inclusion in the legislation of the CLASS (Community Living Assistance Services and Supports) program, a federal long-term care insurance program that the CBO projected would generate significant revenue and little cost during its early years. The HHS announced on October 14, 2011 that it could not certify that the CLASS could be implemented to achieve actuarial balance over 75 years, a statutory requirement for the program to go forward. ${ }^{16}$

In addition, the $\mathrm{CBO}$ projections include large cuts in Medicare spending, which, as noted earlier, the CMS does not believe will be fully achievable (see Figure 2). The cost of Medicaid expansion and premium subsidies also could be greater than projected by the $\mathrm{CBO}$ and projected tax revenues could be lower. ${ }^{17}$ It is therefore arguable whether a repeal of the law would materially aggravate federal budget deficits during the customary 10-year budget horizon.

\section{Effects on Healthcare Spending}

Although the ACA includes numerous provisions for reducing medical expenditures, the law's overriding objective is to expand greatly the number of people with health insurance rather than "bend the cost curve." Provisions to reduce growth in Medicare spending were in significant measure designed to help finance coverage expansion. Given the projected expansion of coverage, it is hardly surprising that the law is projected to increase total health care spending over the next decade. CMS projects that the ACA will increase national health expenditures by \$311 billion during 2010-2019 (CMS, 2010).

The ACA establishes a number of mechanisms that could eventually help reduce Medicare spending growth apart from the specified cuts in reimbursement of Medicare providers, even though the CBO projects little impact of these measures over 10 years. The law authorizes the creation of Accountable Care Organizations that will allow provider groups to share in potential savings from

\footnotetext{
${ }^{16}$ Harrington (2009) provides a brief, pre-passage critique of the CLASS program's likely impact on spending and deficits.

${ }^{17}$ The projections count tax increases and spending cuts that commence prior to increased spending for Medicaid expansion and premium subsidies in 2014, making the 10-year projections more favorable. But the CBO also speculates that reduced taxes and spending from the law beyond 2021 will reduce deficits further. None of the CBO projections consider future actions by the Congress to override previously scheduled cuts in Medicare physician reimbursement, an issue that highlights the economic and political difficulties of implementing previously enacted cuts in payments to providers.
} 
providing Medicare benefits more efficiently. Proposed HHS regulations for such organizations have yet to be finalized. The initial proposed regulations reduced the enthusiasm of many would-be participants. Similarly, the law created the Center for Medicare \& Medicaid Innovation to develop innovative payment models to improve coordination of care and hopefully lower costs. The law established the Patient Centered Outcomes Research Center to fund research on the comparative effectiveness of different medical treatments. Such research might help identify some types of care that are ineffective yet costly compared with alternatives.

Controversially, the law establishes a 15-member Independent Payment Advisory Board (IPAB) that is required beginning in 2014 to submit proposed cuts in Medicare spending to Congress if spending growth exceeds specified targets. The recommendations would be implemented by HHS unless the Congress approved measures to produce equivalent savings or waived this requirement by a supermajority. The law limits significantly the types of actions the IPAB can recommend. It cannot, for example, propose reductions in benefits, increases in beneficiary premiums or co-payments, or cuts in reimbursements to hospitals and certain other providers that were otherwise subject to cuts under the law through 2018-2019. President Obama has proposed lowering the spending growth targets that would trigger action by the IPAB as a means to reduce federal budget deficits. Many Republican and some Democrat members of Congress have proposed eliminating the IPAB.

The ACA imposes an excise tax of 40 percent of health plan costs (aggregate values) in excess of $\$ 10,200$ for individual coverage and $\$ 27,500$ for family coverage beginning in 2018 (subject to certain exceptions, with thresholds indexed for general inflation beginning in 2020). The excise tax will likely encourage many employers to modify their plans to reduce costs and thereby reduce or avoid the tax by increasing cost-sharing and/or adopting more effective care management programs. Those changes would reduce cost growth over time. Many firms already are taking such steps. 


\section{Mandates and Insurance Premiums}

Early evidence suggests that the impact of immediate changes in insurance coverage under the ACA (elimination of pre-existing condition exclusions for children, extension of coverage for dependents to age 26,100 percent coverage of preventive care, and removal/limitation of lifetime/annual benefit limits) have contributed modestly to health insurance premium increases, with larger effects for the individual market than for group coverage. ${ }^{18}$ The longer run effects on health insurance premiums will depend in significant measure on the scope of essential benefits required and the effectiveness of the individual mandate, assuming that the mandate survives court scrutiny. The scope of essential benefits had not been determined. The Institute of Medicine (2011) has recommended that essential benefits be designed to be affordable to health insurance buyers.

The debate over the mandate's constitutionality has played a major role in the ongoing policy debate. Federal appellate courts have divided on whether the individual mandate, which requires people to purchase a privately provided service, violates the Commerce Clause of the U.S. Constitution. The U.S. Supreme Court will likely decide the issue before the November 2012 election and, if it finds the mandate unconstitutional, whether the provision is separable from other parts of the law. The constitutional issue notwithstanding, the effects of an individual mandate depend on numerous factors.

Fewer uninsured and fewer free riders. An individual mandate with meaningful penalties for non-compliance represents a means for significantly increasing the number of people with coverage and improving their access to medical care. A mandate simply requires some people to obtain coverage who otherwise would not. A mandate also facilitates restrictions on health insurance pricing and underwriting that may broaden risk pools by requiring younger/healthier people to buy coverage, thus helping to subsidize the purchase of coverage by older/less healthy people. Moreover, by reducing the elasticity of demand, a mandate conceivably could permit a greater degree of coverage expansion for a given dollar cost of premium subsidies (see below), thus reducing the overall cost of coverage expansion.

\footnotetext{
${ }^{18}$ For example, a late 2010 survey of health insurers suggested these changes could increase average premiums in 2011 by 1-2 percent for group plans and 3-5 percent for individual plans (Aon Hewitt, 2011).
} 
An individual mandate with meaningful penalties can also reduce the free rider problem. With voluntary coverage, many people without insurance receive emergency and/or acute medical care, with some or even all of the costs shifted to other parties. Requiring people to buy coverage reduces the amount of uncompensated care, thus benefitting parties who would otherwise bear those costs.

Implicit taxes and explicit/implicit subsidies. On the other hand, a mandate essentially imposes implicit taxes on people who are required to buy coverage against their will (and above the value of the coverage to them). While this can reduce the free rider problem, significant subsidies are required to avoid a disproportionate burden on low income people. Even with sizable premium subsidies, a mandate will require many people to buy expensive coverage against their will, often at premium rates significantly higher than their expected costs of care when combined with strict restrictions on health insurance underwriting and rating. Younger and healthier people, for example, will be required to pay higher premiums to help finance coverage for older and less healthy people.

The cost of premium subsidies that accompany a mandate will be borne largely by unsubsidized parties and taxpayers, at least partially offsetting any reductions in the burden of uncompensated care. Moreover, because premium subsidies cannot be targeted accurately to people who would fail to buy coverage without a mandate, there necessarily will be some crowding out of unsubsidized coverage. Significant subsidies will inure to some people who would have purchased coverage without the mandate and subsidies, increasing the total cost of subsidies.

Penalties, enforcement, rating restrictions, and adverse selection. A mandate with meaningful penalties for non-compliance is likely desirable if insurers are required to offer coverage without regard to health status. Otherwise, many people will wait to buy coverage until they need expensive care. The resulting "adverse selection" could significantly increase the cost of coverage, encouraging even more people to defer buying coverage. In addition to increasing pressure for subsidies, however, the implicit taxes embedded in an individual mandate create significant pressure to weaken the mandate through 
exemptions, low penalties, and/or lax enforcement. ${ }^{19}$ The weaker is the mandate, the fewer the number of people who will become insured. When combined with restrictions on health insurance underwriting and pricing, a weak mandate will increase adverse selection and average premiums as older and less healthy uninsured people sign up for coverage, while younger and healthier people delay buying coverage until they need costly care.

Required coverage, increased utilization, and increased demand. The individual mandate will put upward pressure on premiums for reasons apart from any adverse selection arising from weak penalties. Any mandate requires specification of the minimum coverage and benefits that will satisfy the mandate. A mandate necessarily requires some government prescription of the types and amounts of medical services that must be insured, such as the minimum essential benefits package under the ACA. The richer are the benefits, the higher will be the premium, and the greater the need for subsidies to make coverage more affordable for people with low to moderate incomes. If the minimum package includes broader benefits for many people than currently purchased, those people will face higher premiums (apart from any premium subsidies that they could receive). Increases in the amount of care insured might have beneficial effects on access and health, but it could also lead to some increase in utilization of low-valued care, a widely acknowledged source of high health care costs. Costs and premiums also could increase if prices rise for certain medical services rise as a result of significant increases in demand for care.

In summary, a mandate can reduce significantly the number of uninsured and mitigate free rider problems. But there also will be repercussions and considerable uncertainty concerning its overall impact on welfare. The potential impact of the ACA's mandate and other health insurance provisions is uncertain, in part because of uncertainty concerning the magnitude of adverse selection. There would appear to be little or no evidence that the Massachusetts mandate, with its penalties for non-compliance, has led to significant adverse selection. However, the Massachusetts' experience on this dimension may

\footnotetext{
${ }^{19}$ Low penalties and lax enforcement characterize mandatory automobile liability insurance, where in many states 10-15 percent or more of all drivers fail to comply with the mandate to buy coverage.
} 
not be informative concerning the likely effects of the ACA. In addition to demographic differences and differences in the details of the laws, relatively few people were uninsured in Massachusetts prior to the 2006 reforms. More important, Massachusetts imposed strong restrictions on health insurance underwriting and rating well before 2006, raising the possibility that its mandate could reduce adverse selection caused by those restrictions. In contrast, the ACA simultaneously restricts underwriting and rating and imposes a mandate.

The CBO's analysis of the U.S. Senate bill that essentially became the ACA estimated that the bill's broader required coverage and attendant increase in utilization of medical care would cause average premiums (before subsidies) to increase for the individual market by 10 to 13 percent by 2016 compared with prior law (CBO, 2009). The CBO noted that the estimated increase would be much larger, 27 to 30 percent, if not for its assumptions of significant savings in administrative costs from new insurance market rules and some shift towards younger buyers and those who would use less care than the currently insured population.

The CBO speculated that the extent of adverse selection from low penalties for violating the mandate "is likely to be limited." Those low penalties generated substantial pushback by private health insurers, who had previously agreed to support most of the proposed insurance underwriting and rating restrictions provided they were coupled with a strong mandate. Two industry sponsored studies predicted substantially higher medical costs and premium increases for individual coverage, in significant part due to increased utilization of services and adverse selection from the weak mandate combined with underwriting and rating restrictions (PricewaterhouseCoopers, 2009, Oliver Wyman, 2009).

If the U.S. Supreme Court declares the mandate unconstitutional but allows the ACA's other insurance market provisions to stand, the amount of adverse selection associated with the law's underwriting and rating restrictions would almost certainly increase as some young and/or healthy people who would have bought coverage with a mandate will not do so without. However, the extent of the increase and the attendant effects on premiums are uncertain. One view is that some change in the law to reduce adverse selection (such as a penalty for not buying coverage on a timely basis) would be essential. 
An alternative view is that the increase in adverse selection would likely be modest because the current law's penalties for non-compliance are already so low.

\section{Minimum Medical Loss Ratios and Health Insurance Rate Review}

The ACA's minimum medical loss ratio (MLR) and health insurance rate review provisions establish direct and indirect federal price controls on private health insurance. ${ }^{20}$ The HHS issued 300 pages of minimum MLR regulations (adopting recommendations by the National Association of Insurance Commissioners) in November, 2010 (Department of Health and Human Services, 2010). ${ }^{21}$ The regulations include detailed specification of expenditures on "activities that improve health care quality," which can be counted toward meeting the minimums. The regulations also enumerate expenses that cannot be counted, including spending on utilization review and developing provider networks. In general, expenditures that increase health care costs and premiums can be counted; many expenditures that help control costs and premiums cannot, raising concern that the regulations will put upward pressure on costs and premiums.

Proponents of the minimum MLR regulations believe they will assist consumer choice and help consumers get more value for their premiums. ${ }^{22}$ The counterargument is that they involve (1) costly and bureaucratic micromanagement of the types and amounts of insurer spending at considerable compliance cost, (2) less competition and consumer choice, (3) disincentives for insurers to adopt certain strategies that could lower premiums by controlling medical costs, and (4) significant risk of unintended consequences, including effects on plan design and insurer/provider relationships.

State insurance regulators who believe that application of the 80 percent minimum medical loss ratio would destabilize their individual market are allowed to seek waivers from the HHS. The NAIC has

\footnotetext{
${ }^{20}$ Harrington (2010b) critiques these provisions and their likely effects. Also see Robinson (1997).

${ }^{21}$ To prevent serious disruptions in the market for limited-benefit plans with annual limits of $\$ 250,000$ or less and for specialized health plans covering U.S. citizens residing abroad, the HHS permitted multiplying their loss ratios by two, which is equivalent to halving the required minimums.

${ }^{22}$ Cebul, et al. (2010) develop and estimate a model in which costly search leads insurers to excessive administrative costs and profits, which in principle could be reduced with minimum MLR requirements. The evidence is less than dispositive given the authors' inability to control completely for differences across insurers in average medical costs of their policyholders.
} 
urged HHS Secretary Sebelius to defer to those requests. The HHS has granted a number of waivers (Kentucky, Iowa, Maine, New Hampshire, and Nevada), denied two (Delaware and North Dakota), and is reviewing others. In a move that would extend the scope of minimum MLR regulations, the HHS requested that Florida establish a minimum MLR of 85 percent for Medicare Advantage plans (private plans providing Medicare benefits).

With respect to the ACA's rate review provisions, HHS regulations set 10 percent as the threshold for "unreasonable" rate increases beginning September 1, 2011, with state-specific thresholds to be considered in the future. The law authorizes the HHS to assume responsibility for rate review if it deems that a state does not have an effective review process. Based on its review of state rate review procedures, the HHS will conduct reviews in six states (Alabama, Arizona, Louisiana, Missouri, Montana, and Wyoming; see CCIIO, 2011). Insurers with rate increases that are deemed unreasonable after the review process is concluded risk exclusion from the exchanges in 2014.

Research and experience for automobile insurance, workers' compensation insurance, and more recently, homeowners' insurance in catastrophe prone states, indicate that rate regulation for those coverages cannot materially lower average rates without reducing quality and availability of coverage and/or causing a significant numbers of insurers to exit the market. ${ }^{23}$ Because individual and small group health insurance markets generally are much more concentrated than property/casualty insurance markets, the relevance of this experience and research for health insurance may be questioned. Nonetheless, it is far from clear that the ACA's rate review provisions and attendant regulations can be expected to increases consumers' choices, increase quality, or significantly lower premiums. The rate review provisions and regulations risk further politicization of rate review, with an attendant risk of market disruptions, especially if other ACA provisions put upward pressure on premiums.

\footnotetext{
${ }^{23}$ See, for example, Cummins (2002) and Harrington (2002).
} 


\section{Other Immediate Reforms}

The experience with other immediate reforms included in the ACA has been mixed. In several cases, implementation suggests that the provisions reflected a lack of understanding of the economics of health insurance markets and the potential for unintended consequences.

Prohibition of rescissions absent fraud. As explained earlier, the ACA prohibits health policy rescissions absent fraud (intent to deceive) by the applicant. State law already prohibited insurers from cancelling coverage as a result of people getting sick. Insurers could legally rescind coverage for fraud or, without having to prove fraud, if an insurer could prove that an applicant's statement regarding a health condition was false and affected the insurer's decision to offer coverage or the premium charged. Requiring insurers to prove fraud in each case would be expected to produce some increase in premiums and, prior to 2014, some reduction in offers of coverage. Little is known about the extent to which either has occurred. The relative silence on this provision after enactment of the ACA contrasts with the significant attention it received during 2009 and early 2010.

Dependent coverage. The requirement that parents' health plans cover children up to age 26 appears to have been a practical and political success, with many young adults being added to their parents' coverage. The costs of funding the coverage expansion and premium increases are relatively small, opaque, and spread broadly among health plan enrollees, including the majority who receive no benefit.

Annual benefit limits. The law's restrictions on health plans' annual benefit limits have thus far proved substantially unworkable. The HHS waived the initial restrictions for hundreds of limited-benefit plans to minimize disruptions and preserve the market for such coverage, at least for the time being. The economic reality, which the drafters apparently failed to appreciate, is that many people with low to moderate incomes prefer plans with limited benefits compared with having to pay higher premiums or receive lower wages for unlimited coverage, and that aggressive increases in limits would harm the participants. 
Pre-existing condition exclusions for children. The law's prohibition of excluding or charging higher premiums for pre-existing conditions for children under age 19 led many health insurers to stop offering "child-only" coverage. Regulators and state legislatures have been pursuing a variety of approaches to encourage or force insurers to offer coverage, including new rules that allow families to sign up for such coverage only during specified open enrollment periods and, in some states, requiring insurers to offer child only coverage if they sell any individual health insurance.

Temporary pre-existing condition insurance plans. An noted, the ACA's state-level plans, named Pre-Existing Condition Insurance Plans (PCIPs), offering coverage at subsidized rates to people with pre-existing conditions that have been uninsured for at least six months are intended as a stopgap until the law's prohibitions on health insurance underwriting and pricing based on health status become effective in 2014. Twenty-three states and Washington, D.C. elected to have plans administered by the federal government; 27 states elected to administer their own plans. The first plans opened for business on July 1, 2010; all states had plans by October 25, 2010.

The CBO predicted that the plans would average enrollment of 200,000 during 2011-2013 under the $\$ 5$ billion cap on federal spending for the plans contained in the law, and that enrollment would grow from 400,000 in 2011 to 600,000-700,000 in 2013 if $\$ 5$ billion to $\$ 10$ billion more were spent (CBO, 2010). In April 2010, the CMS chief actuary estimated that 375,000 people would sign up in 2010 and that the $\$ 5$ billion would be exhausted soon after (CMS, 2010). As of August 31, 2011, however, only 34,000 people had signed up for the plans (HealthCare.gov, 2011b). Pennsylvania's plan was the largest, with close to 4,000 enrollees. A majority of states had fewer than 500 enrollees.

The explanation offered for the negligible enrollment by the HHS and many observers (e.g., GAO, 2011) is that coverage is too expensive and limited and that people were unaware of the plans. As negligible enrollment became apparent in the fall of 2010, the HHS announced that it would introduce new coverage options, cut rates, and increase outreach to attract more enrollees. Plan premiums, while heavily subsidized, clearly are higher than many people are willing to pay, especially in some states. But another explanation for low enrollment is that the magnitude of the pre-existing conditions problem in 
health insurance is considerably smaller than asserted during the debate over the ACA. ${ }^{24}$ It suggests that the main problem is high average costs of health care, not pre-existing conditions and insurers'

underwriting and pricing practices. It also suggests that burden on taxpayers of funding expanded pools for high risk applicants may be relatively modest if the ACA is repealed and replaced with a marketoriented reform program.

\section{Market-Oriented Alternatives to the ACA}

There are two broad paths to achieving sustainable growth in health care costs: (1) progressively increasing government controls on reimbursement and delivery, with access to care determined heavily by legislatures, regulatory agencies, and policy experts; and (2) market-oriented solutions that give many people more responsibility for their care and coverage decisions, thus reducing spending through decentralized decisions by thousands of firms and millions of individuals. I agree with those who believe that the ACA represents a significant step along the first path. The 2012 elections will likely determine whether the country continues down that path or instead modifies or replaces the ACA with more marketbased reforms.

If given the opportunity by the electorate, Republican initiatives to "repeal and replace" the ACA will likely emphasize increased consumer choice and responsibility to expand incentives for efficient cost control. While the details are uncertain and could depend on broader economic proposals regarding taxes and spending, a market-oriented agenda for replacing the ACA's insurance reforms would likely include some combination of the following initiatives:

1. Change the tax treatment of health insurance to encourage cost control and equalize treatment of employer-sponsored coverage and portable, individual coverage, including expanded health savings accounts, and without increasing the overall federal and state tax burden.

2. Improve portability of coverage and access to coverage through state-level high risk plans for people with pre-existing conditions, while still providing incentives for people to obtain coverage before they need care.

\footnotetext{
${ }^{24}$ Despite the low enrollment figures, the HHS released a polemic in 2011 claiming that 25 million of the uninsured had pre-existing conditions and that 129 million Americans could be denied affordable coverage without the ACA (HealthCare.gov, 2011a).
} 
3. Promote informed health insurance competition and consumer choice with pro-competitive disclosure and regulation at the state level, including promoting greater interstate competition in health insurance, without federal minimum MLR rules or federal oversight of rate review.

4. Enact medical liability reform to reduce providers' risk and the extent of defensive medicine.

While not necessarily part of any plan to repeal and replace the ACA, a Republican sweep in the 2012 elections would likely lead to serious debate within the next few years about two additional proposals. One proposal would be to transform Medicare for people under age 50 or 55 to provide risk and income adjusted premium support to select among competing private coverage plans and/or a choice of government plans with different degrees of cost-sharing and care management. The second proposal would transform Medicaid by changing the program to one of block grants, giving the states substantially more flexibility to design and implement their own programs. In the tradition of the ACA, such proposals would clearly be controversial. 


\section{References}

American Medical Association (2007), Competition in health insurance - A comprehensive study of U.S. markets, 2007 update, The American Medical Association.

America's Health Insurance Plans (AHIP) (2009), Individual health insurance 2009 - A comprehensive survey of premiums, availability, and benefits, AHIP Center for Policy Research, October.

Aon Hewitt (2011), 2011 Health Insurance Trend Driver Survey, Aon Corporation.

Boards of Trustees, Federal Hospital Insurance and Federal Supplementary Medical Insurance Trust Funds (2009), 2009 Annual Report.

Boards of Trustees, Federal Hospital Insurance and Federal Supplementary Medical Insurance Trust Funds (2011), 2011 Annual Report.

Cebul, R., J. Rebitzer, L. Taylor, and M. Votruba (2008), Unhealthy Insurance Markets: Search Frictions and the Cost and Quality of Health Insurance, NBER Working Paper No. 14455, October.

Center for Consumer Information and Insurance Oversight (CCIIO) (2011), Health insurance rate review: lowering costs for American consumers and businesses, http://cciio.cms.gov.

Center for Medicare \& Medicaid Services (CMS) (2010), Estimated financial effects of the "Patient Protection and Affordable Care Act, memorandum from Richard Foster, Chief Actuary, April 22. (2011), Projected Medicare expenditures under an illustrative alternative scenario with alternative payment updates to Medicare providers, memorandum from John Shatto and M. Clemens, May 13.

Congressional Budget Office (CBO) (2009), An analysis of health insurance premiums under the Patient Protection and Affordable Care Act, November 30.

(2010), Letter from Douglas Elmendorf, Director, to Senator Michael Enzi on temporary preexisting insurance pools, June 21.

(2011a), Statement of Douglas W. Elmendorf, Director, CBO's Analysis of Major Health Care Legislation Enacted in March 2010, before the Subcommittee on Health, Committee on Energy and Commerce, U.S. House of Representatives, March 30, 2011.

(2011b), Letter from Douglas Elmendorf, Director, to Speaker of the House, John Boehner, on revenue effects of H.R. 2, Repealing the Job-Killing Health Care Law Act, February 18, 2011.

Conover, C. and T. Miller (2010), Why a public plan is unnecessary to stimulate competition, AEI Working Paper No. 162, January.

Cummins, J. D., Property-liability insurance price deregulation: The last bastion, in J. David Cummins, ed., Deregulating Property-Liability Insurance (Washington, D.C.: AEI-Brookings Joint Center for Regulatory Studies).

Dafny, L. (2008), Are health insurance markets competitive? A direct test of price discrimination, NBER Working Paper 14572.

Dafny, L., M. Duggan, and S. Ramanarayanan (2009), Paying a premium on you premium: Consolidation in the U.S. health insurance industry, NBER Working Paper 15434.

Department of Health and Human Services (HHS) (2010), 45 CFR Part 158, Health Insurance Issuers Implementing Medical Loss Ratio (MLR) Requirements Under the Patient Protection and Affordable Care Act, November. 
Donahue, D. (2010), Health plans see revenue shift away from commercial, Healthcare Business Strategy, Mark Farrah Associates, May 10.

Gaynor, M. and R. Town (2011), Competition in health care markets, NBER Working Paper 17208, July.

Government Accountability Office (2009), Private health insurance: 2008 survey results on number and market share of carriers in the small group health insurance market, GAO-09-363R, February 27.

(2011), Pre-existing condition insurance plans: program features, early enrollment and spending trends, and federal oversight activities, GAO-11-662, July 27.

Hadley, J., J. Holahan, T. Coughlin, and D. Miller (2008), Covering the uninsured in 2008: Current costs, sources of payment, and incremental costs, Health Affairs 27: w399-w425.

Harrington, S. (2002), Effects of prior approval regulation in automobile insurance, in J. David Cummins, ed., Deregulating Property-Liability Insurance (Washington, D.C.: AEI-Brookings Joint Center for Regulatory Studies).

(2009), Congress's long-term care bomb, The Wall Street Journal, December 13.

(2010a), The health insurance reform debate, Journal of Risk and Insurance 77: 5-38. (Earlier version distributed as American Enterprise Institute Working Paper No. 161, December 2009).

(2010b), Regime change for health insurance regulation: rethinking rate review, medical loss ratios, and informed competition, American Enterprise Institute, December.

HealthCare.gov (2011a), At risk: pre-existing conditions could affect 1 in 2 Americans, http://www.healthcare.gov.

HealthCare.gov (2011b), State by state enrollment in the Pre-Existing Condition Insurance Plan, as of August 31, 2011, http://www.healthcare.gov.

Kaiser Family Foundation and Health Research and Educational Trust (HRET) (2009), Employer Health Benefits 2009 Annual Survey. (2011), Employer Health Benefits 2011 Annual Survey.

Kaiser Family Foundation (2009), The uninsured - A primer, key facts about insurance and Supplementary data tables, October. (2011a), Establishing health insurance exchanges: An update on state efforts, July. (2011b), How competitive are state insurance markets? October. (2011c), Summary of new health reform law, updated April 15.

Levy, H. and D. Meltzer (2009), The impact of health insurance on health. Annual Review of Public Health 29.

McKinsey \& Company (2008), Accounting for the cost of U.S. health care: A new look at why Americans spend more, McKinsey Global Institute, December.

Moriya, A., W. Vogt, and M. Gaynor, 2010, Hospital prices and market structure in the hospital and insurance industries, Health Economics, Policy, and Law 5: 459-479.

National Institutes for Health Care Management (NIHCM) (2008), Understanding the uninsured: Tailoring policy solutions for different subpopulations, NIHCM Policy Issue Brief, April.

Oliver Wyman (2009), Insurance reforms must include a strong individual mandate and other key provisions to ensure affordability, October. 
PricewaterhouseCoopers (2009), Potential impact of health reform on the cost of private health insurance coverage, October.

Robinson, J. (1997), Use and abuse of the medical loss ratio to track health plan performance, Health Affairs 16: 176-187.

Robinson, J. (2004), Consolidation and the transformation of competition in health insurance, Health Affairs 23: 11-24. 
Figure 1

U.S. Health Care Spending as Percent of GDP, 1965-2010

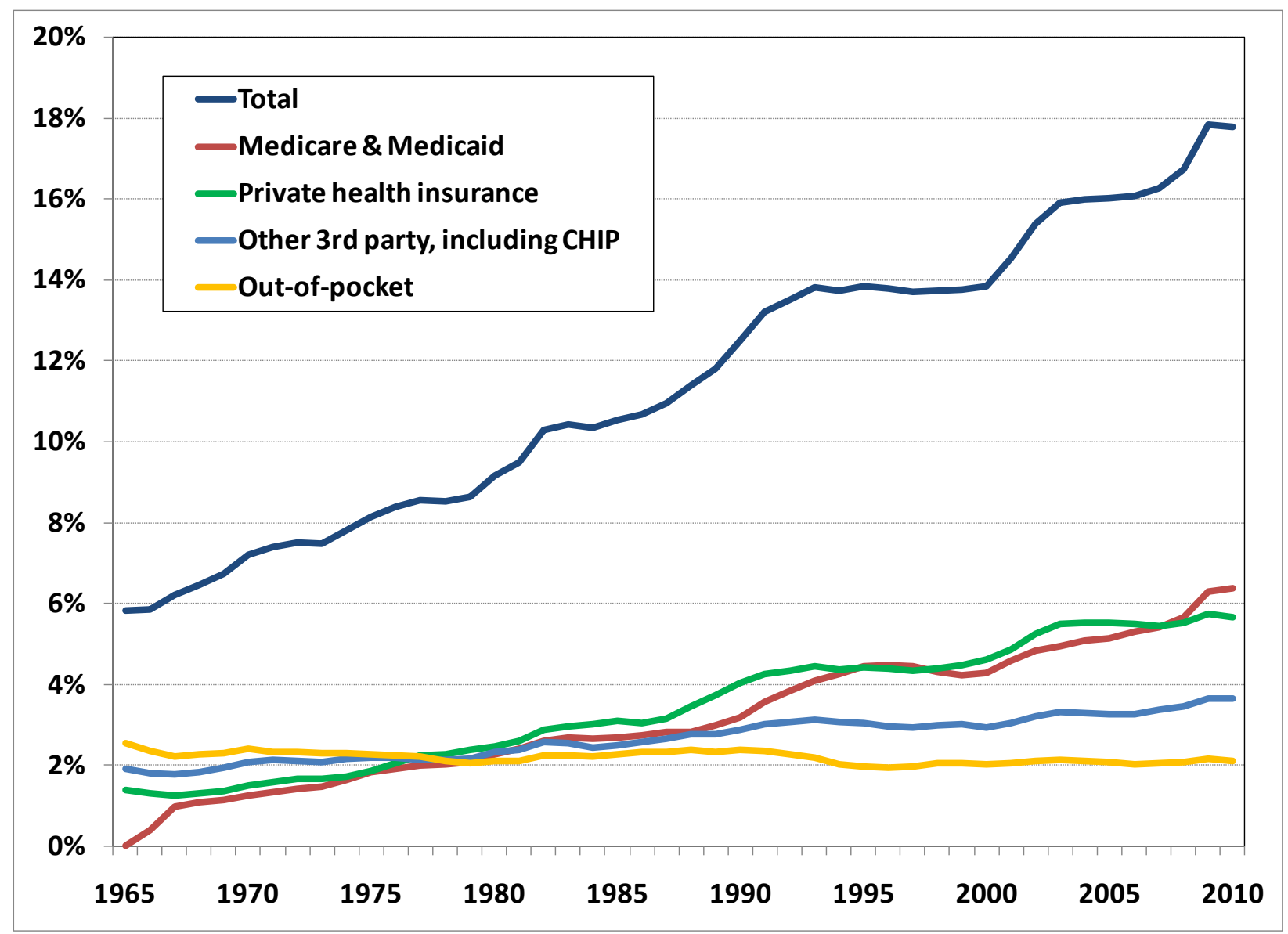

Author's calculations with national health expenditure data: National Health Expenditure (NHE) Amounts by Type of Expenditure and Source of Funds: Calendar Years 1965-2020 in PROJECTIONS format. Projections for 2010 (based on the 2009 version of the NHE released in January 2011). 
Figure 2

Projected Medicare Spending as Percent of GDP, 2010-2050

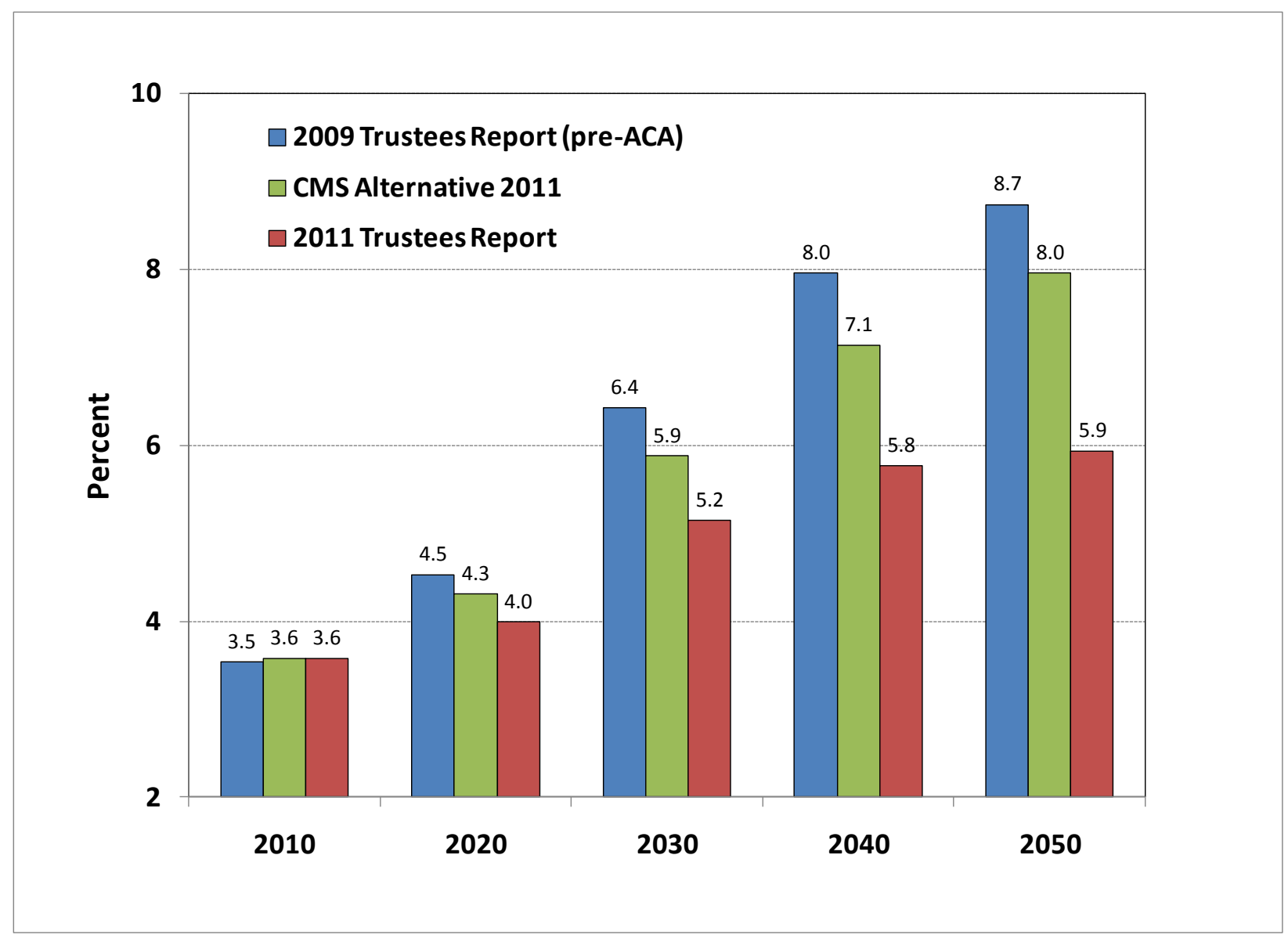

Boards of Trustees of the Federal Hospital Insurance and Federal Supplementary Medical Insurance Trust Funds (2009 and 2011) and CMS (2011). 
Figure 3

Estimated Percentages of U.S. Under Age 65 Population by Health Insurance Status

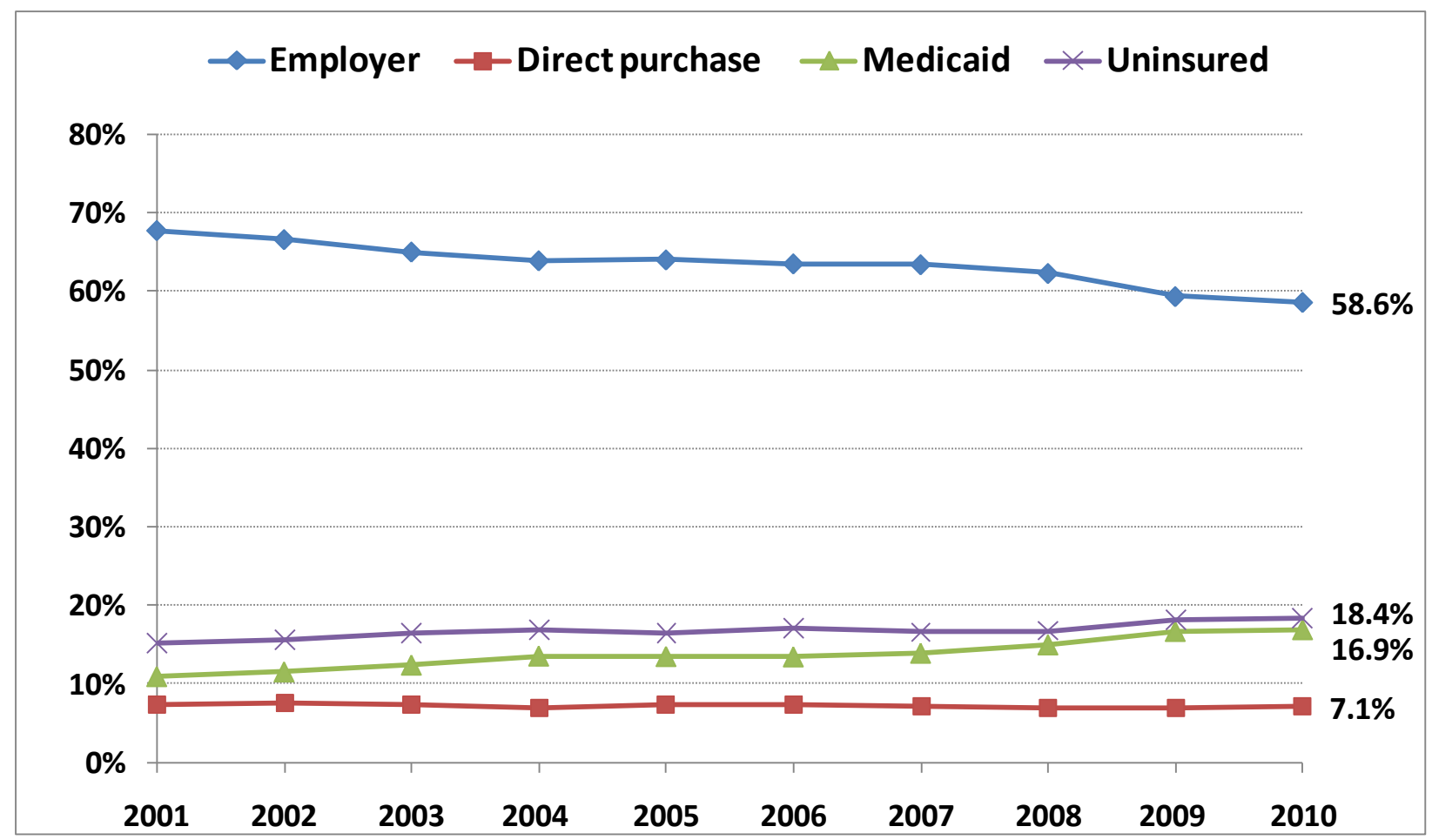

U.S. Census Bureau. Table HIB-2. Health Insurance Coverage Status and Type of Coverage All Persons by Age and Sex: 1999 to 2010. People as of March of the following year.

http://www.census.gov/hhes/www/hlthins/data/historical/HIB tables.html. 
Figure 4

Estimated Percentages Uninsured by Age Group

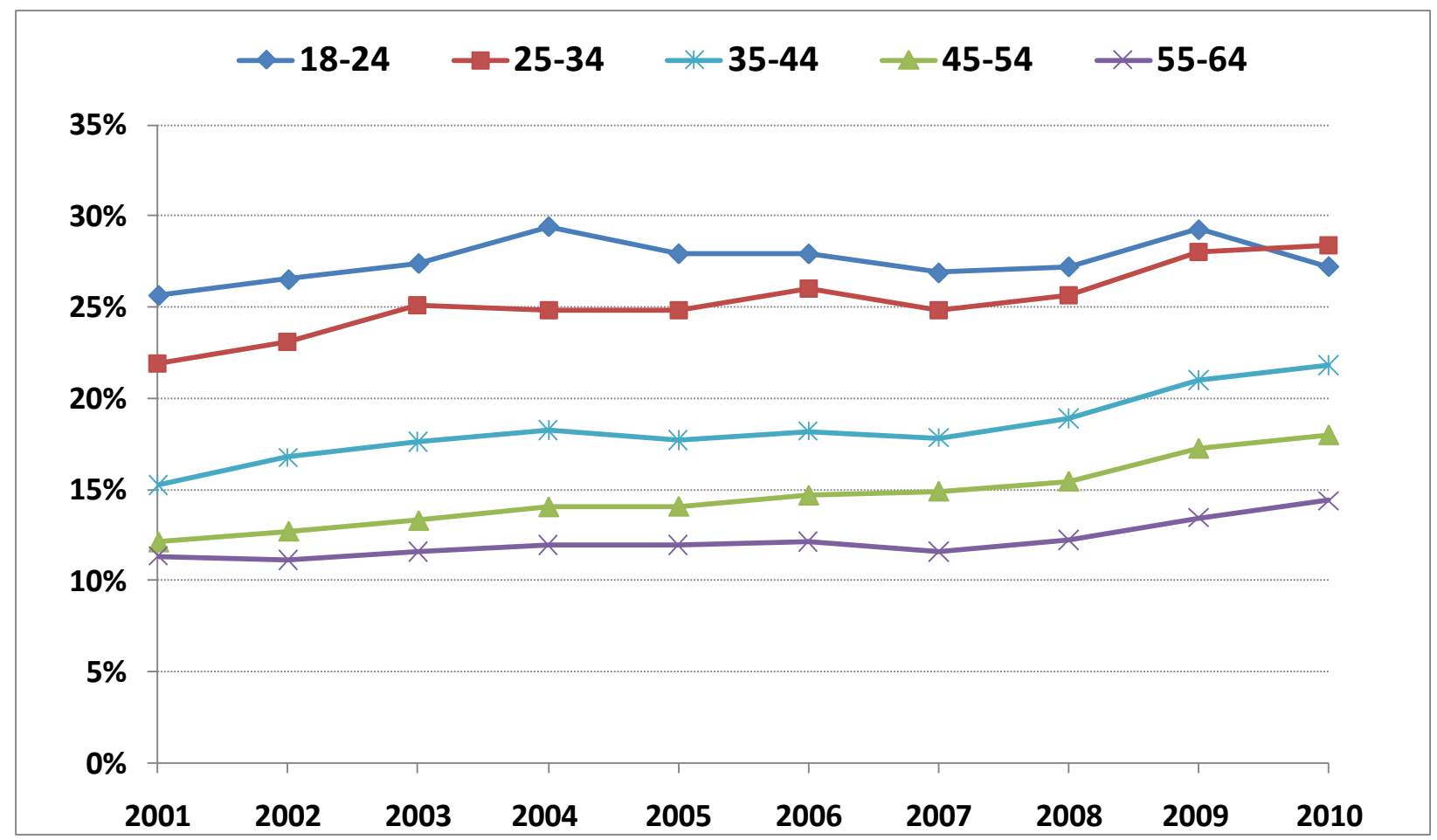

U.S. Census Bureau. Table HIB-2. Health Insurance Coverage Status and Type of Coverage All Persons by Age and Sex: 1999 to 2010. People as of March of the following year.

http://www.census.gov/hhes/www/hlthins/data/historical/HIB tables.html. 
Figure 5

U.S. Out-of-Pocket Spending as Percent of Total Health Care Spending, 1965-2010

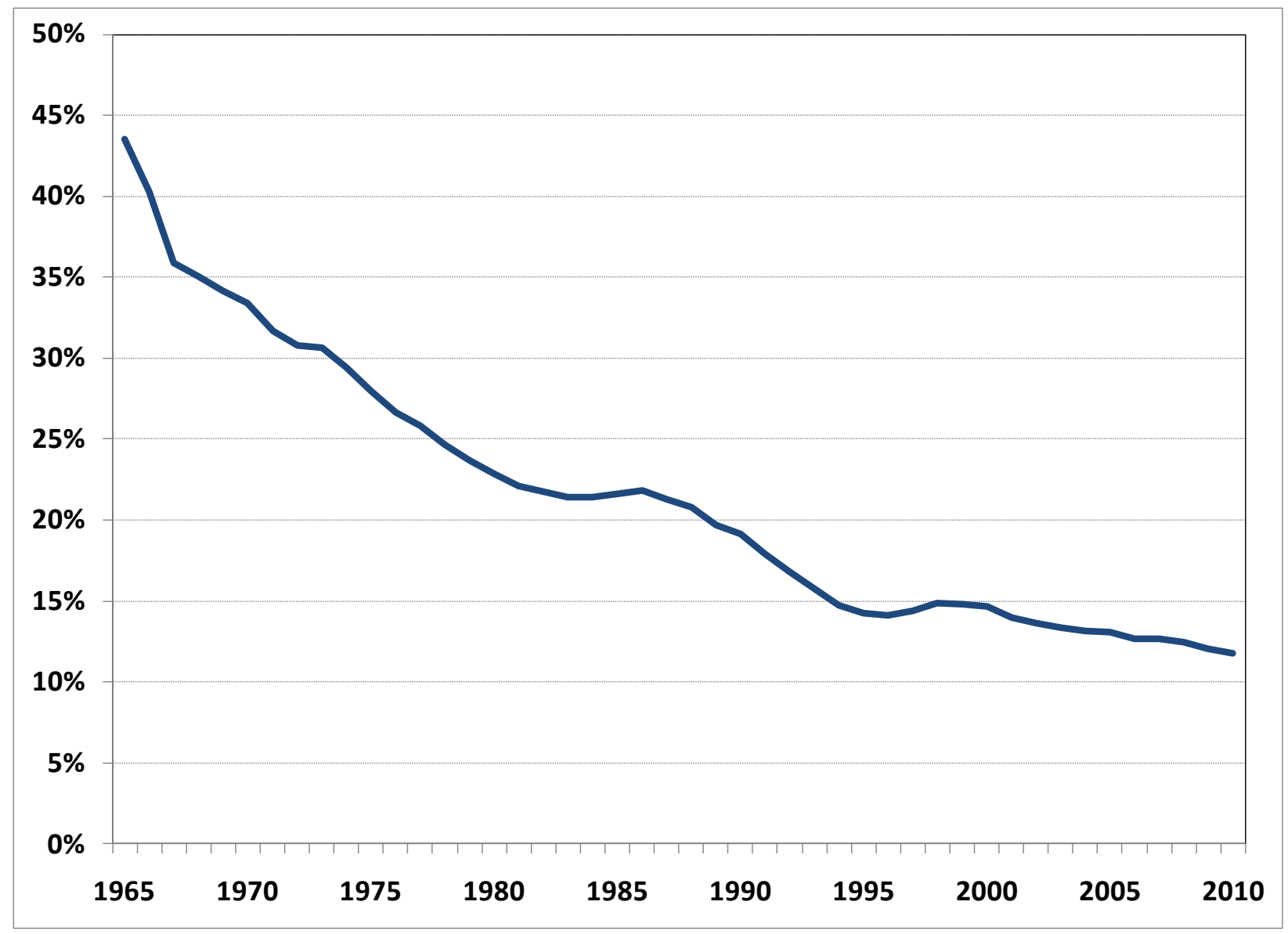

Author's calculations with national health expenditure data: National Health Expenditure (NHE) Amounts by Type of Expenditure and Source of Funds: Calendar Years 1965-2020 in PROJECTIONS format. Projections for 2010 (based on the 2009 version of the NHE released in January 2011). 
Figure 6

Estimated U.S. Medical Loss Ratio for Private Health Insurance, 1965-2010 (including premium equivalents for self-funded plans)

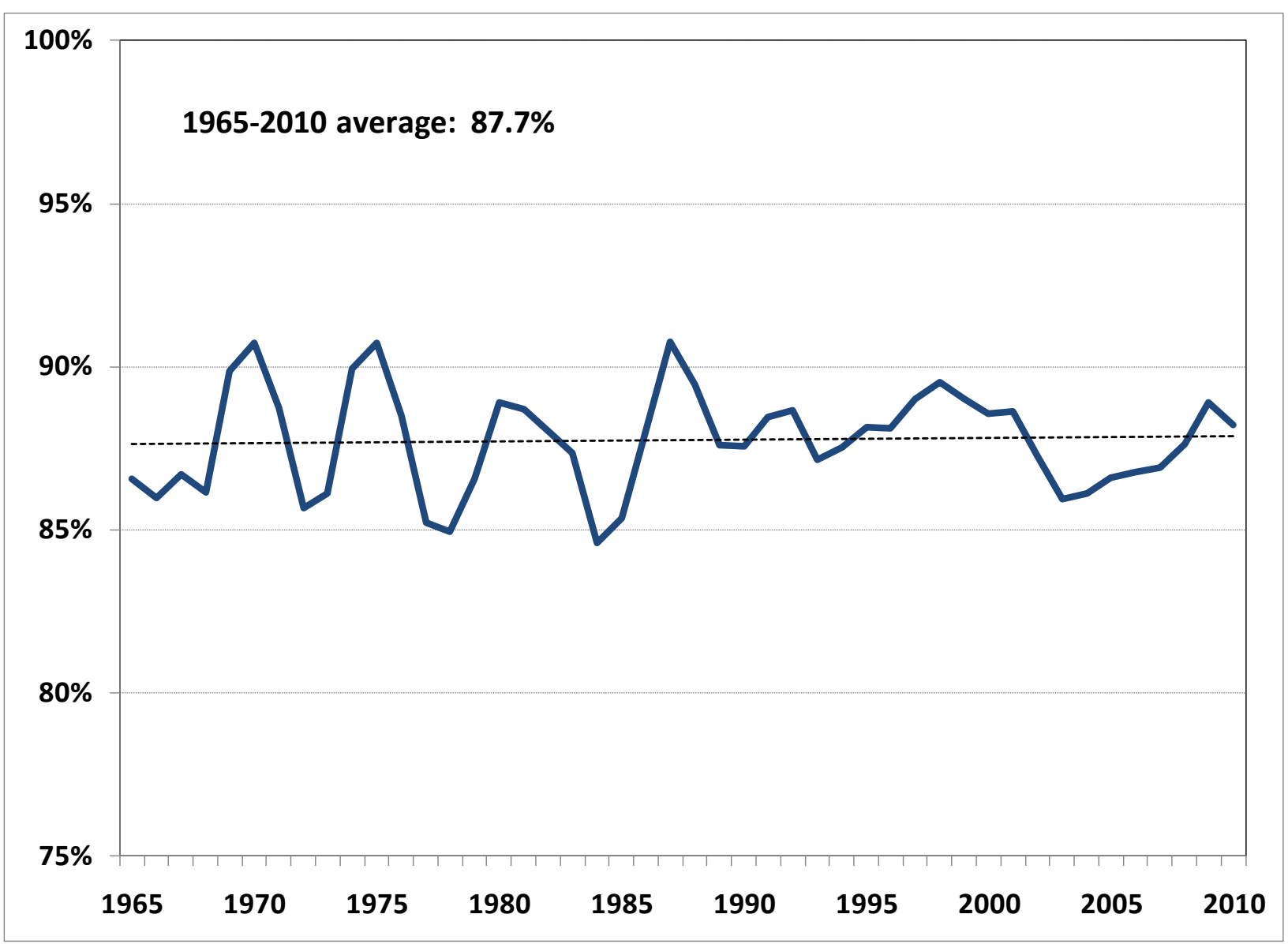

Author's calculations with national health expenditure data: National Health Expenditure (NHE) Amounts by Type of Expenditure and Source of Funds: Calendar Years 1965-2020 in PROJECTIONS format. Projections for 2010 (based on the 2009 version of the NHE released in January 2011). 
Figure 7

Congressional Budget Office Cost Projections for the ACA, 2012-2021

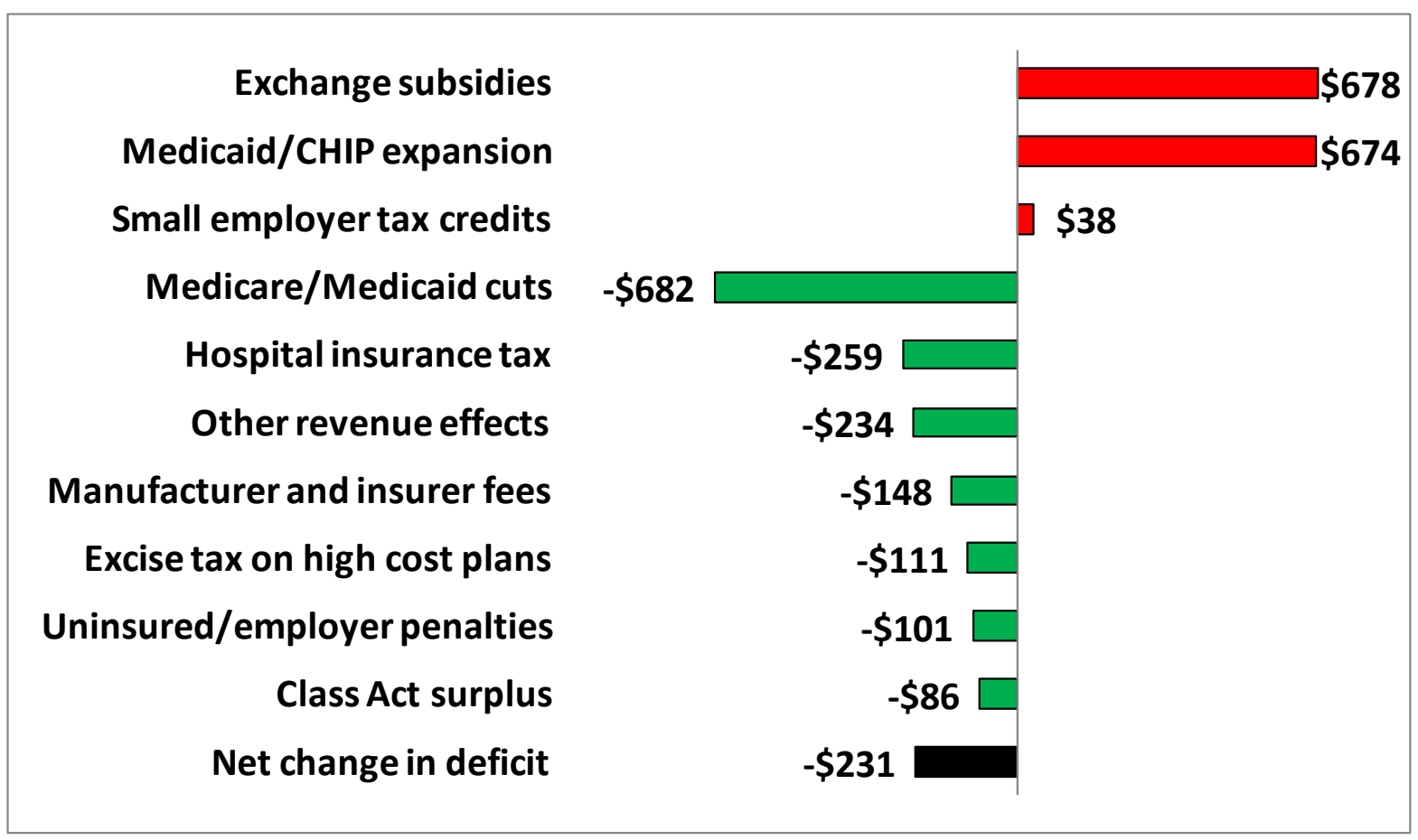

H.R. 2, Repealing the Job-Killing Health Care Law Act, Cost estimate for the act as passed by the House of Representatives on January 19, 2011, http://www.cbo.gov/doc.cfm?index=12069 , CBO (2011b). 
Figure 8

Congressional Budget Office Projections of Insured Population by Type of Coverage

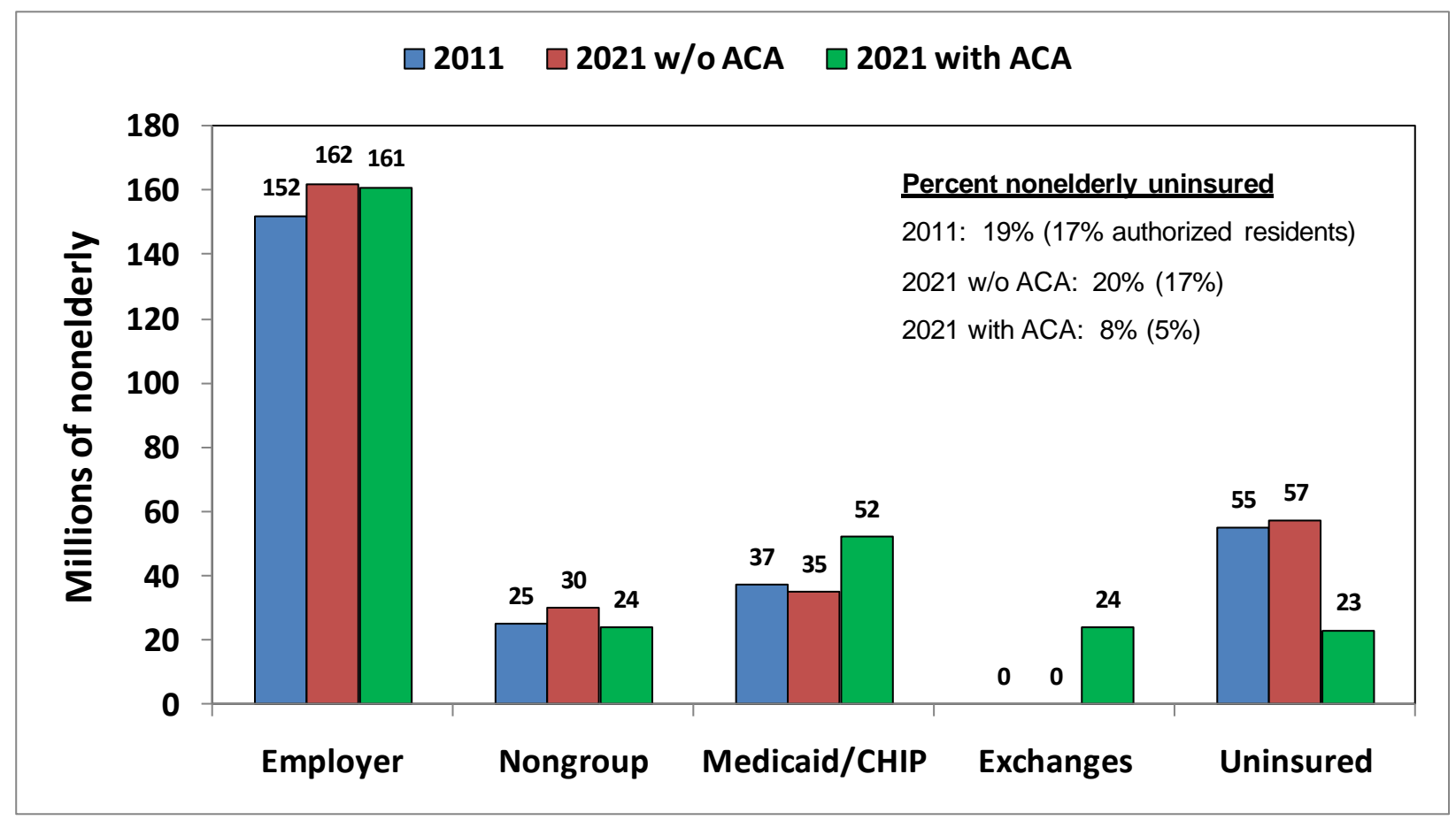

Statement of Douglas W. Elmendorf, Director, CBO's Analysis of the Major Health Care Legislation Enacted in March 2010, before the Subcommittee on Health, Committee on Energy and Commerce, U.S. House of Representatives, March 30, 2011 (CBO, 2011a). 